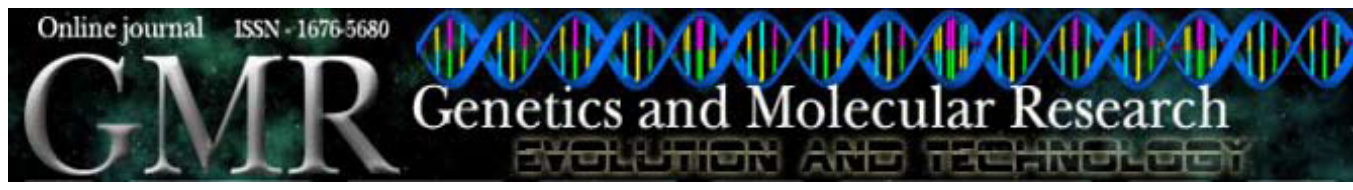

\title{
Incidence of fibroblast growth factor receptor 3 gene (FGFR3) A248C, S249C, G372C, and T375C mutations in bladder cancer
}

\author{
Y. Dodurga ${ }^{1}$, C. Tataroglu ${ }^{2}$, Z. Kesen ${ }^{3}$ and N.L. Satiroglu-Tufan ${ }^{4}$ \\ 'Department of Medical Biology, School of Medicine, Pamukkale University, \\ Denizli, Turkey \\ ${ }^{2}$ Department of Pathology, School of Medicine, Adnan Menderes University, \\ Aydın, Turkey \\ ${ }^{3}$ Department of Pathology, Denizli State Hospital, Denizli, Turkey \\ ${ }^{4}$ Department of Medical Genetics, School of Medicine, Pamukkale University, \\ Denizli, Turkey
}

Corresponding author: N.L. Satiroglu-Tufan

E-mail: nltufan@pamukkale.edu.tr

Genet. Mol. Res. 10 (1): 86-95 (2011)

Received September 3, 2010

Accepted December 9, 2010

Published January 18, 2011

DOI 10.4238/vol10-1gmr923

\begin{abstract}
Bladder cancer is the most frequent cancer of the urinary system. Fibroblast growth factor receptors (FGFR) belong to the tyrosine kinase family and have important roles in cell differentiation and proliferation and embryogenesis. FGFR3 is located on chromosome $4 \mathrm{p} 16.3$, and missense mutations of FGFR3 are associated with autosomal dominant human skeletal disorders and have some oncogenic effects. We examined the incidence of FGFR 3 thanatophoric dysplasia mutations located in exon 7, A248C and $\mathrm{S} 249 \mathrm{C}$, and in exon 10, G372C and T375C, and their correlation with clinical-pathological parameters in bladder carcinoma patients. Fifty-six paraffin-embedded specimens of transitional cell carcinoma of the urinary bladder were included in this study. Analysis of FGFR3 thanatophoric dysplasia mutations located in exon 7, A248C and S249C, and in exon 10, G372C and T375C, was performed by PCR-
\end{abstract}


restriction fragment length polymorphism (RFLP) analysis and DNA sequencing. FGFR3 thanatophoric dysplasia mutations located in exon 7, A248C and S249C, and in exon 10, G372C and T375C, were detected in 33 of the 56 patients (heterozygous mutant). Among the 56 transitional cell carcinomas, missense point mutations were detected in seven of them at codon A248C, 28 of them at codon S249C, and three of them at codon $\mathrm{T} 375 \mathrm{C}$, similar to data from previous reports. When the results of the FGFR3 thanatophoric dysplasia mutations located in exon 7, A248C and S249C and in exon 10, G372C and T375C, were analyzed one by one or as a group, despite the findings of previous research reports, our data suggest that these mutations are detected homogenously regardless of the tumor classification and tumor grade.

Key words: Bladder carcinoma; Fibroblast growth factor receptor 3; Mutation; PCR; DNA sequencing; Transitional cell carcinoma

\section{INTRODUCTION}

Urinary bladder cancer is the fourth most common cancer type in men and the ninth most common cancer in women. More than $90 \%$ of bladder tumors are transitional cell carcinomas. Approximately $80 \%$ of transitional cell carcinomas are confined to the epithelium (pTa, CIS) or lamina propria (pT1) at initial diagnosis, but the remaining $20 \%$ invade the muscularis propria (pT2, pT3, pT4). pTa lesions (papillary tumors) are the most common form of bladder carcinoma (Billerey et al., 2001). The expression and mutational status of fibroblast growth factor receptor 3 ( $F G F R 3$ ) has been analyzed in a series of bladder carcinomas. Frequent activating mutations of FGFR 3 in human bladder carcinomas have been analyzed for the first time, and it was suggested that FGFR3 is involved in epithelial tumorigenesis (Cappellen et al., 1999). Mutations of $F G F R 3$ have also been reported in more than $50 \%$ of primary bladder urothelial cell carcinomas, especially in low-grade and low-stage papillary tumors (Sugano and Kakizoe, 2006). Detection of FGFR3 mutation would be useful for low-grade and low-stage urothelial cell carcinomas in urine due to the higher frequency of this mutation in superficial bladder cancers.

The identification of mutations in FGFR3 indicates an important role in bladder carcinogenesis (Cappellen et al., 1999). FGFR3 belongs to the tyrosine kinase receptor family, which also includes FGFR1, 2 and 4 (Basilico and Moscatelli, 1992). They play important roles in cell proliferation and differentiation and embryonic development. These receptors have two or three extracellular immunoglobulin-like domains, a transmembrane domain and two tyrosine-kinase domains. The human FGFR3, located on chromosome 4p16.3, consists of 19 exons and 18 introns (Perez-Castro et al., 1997). Alternative mRNA splicing mechanisms also produce different receptor isoforms, including FGFR3b and FGFR3c, which have different tissue expressions. FGFR3b is expressed in epithelial cells, whereas FGFR3c is the form found in chondrocytes. Specific point mutations in the FGFR3 gene's different domains are associated with autosomal dominant human skeletal disorders such as severe achondroplasia with developmental delay and acanthosis nigricans (SADDAN), hypochondroplasia, achondroplasia, and thanatophoric dysplasia (Jaye, 1992; Johnson and Williams, 1993). 
These mutations leading to constitutive activation of the receptor have been demonstrated in several reports (Partanen et al., 1993). Some mutations are involved in cell proliferation and differentiation by also activating the receptor tyrosine phosphorylation without a ligand. With this activity, an oncogenic role has been proposed for FGFR3 in multiple myeloma (Chesi et al., 2001). In multiple myeloma, which is a lymphoid neoplasm, a chromosomal translocation $(\mathrm{t}(4 ; 14)$ (p16.3; $\mathrm{q} 32.3))$ with breakpoints on $4 \mathrm{p} 16$ located $50-100 \mathrm{~kb}$ centromeric to FGFR 3 is present in $20-25 \%$ of tumors, and associated with overexpression of FGFR3. Little is known about the role of FGFR3 in epithelial carcinomas, which account for $90 \%$ of malignant neoplasms (Partanen et al., 1993).

Studies with low-grade papillary urothelial carcinoma showed frequent genetic alterations on chromosome 9 , whereas chromosomal changes more specifically associated with aggressive bladder cancer (loss of 17p, 2q, 4p, 11p) were uncommon (Chow et al., 2000; Obermann et al., 2003). In a research study on patients with urothelial hyperplasia in association with low-grade and/or high-grade urothelial carcinomas, a FGFR3 mutation was identified in two of the four hyperplasias accompanied by low-grade papillary urothelial carcinoma (Van Oers et al., 2006), providing support to the view that some lesions with papillary urothelial hyperplasia in patients with bladder cancer represent a neoplastic lesion. Furthermore, genetic alterations have frequently been observed in the normal urothelium of patients with low-grade bladder cancer (Lopez-Beltran et al., 2008).

FGFR3 is expressed in normal urothelium and bladder cancer, and it is suggested that the mutant FGFR3 gene may have an oncogenic role in bladder cancer pathogenesis (Cappellen et al., 1999). In view of these findings, we investigated the incidence of FGFR3 TD mutations located in exon 7, A248C and S249C, and in exon 10, G372C and $\mathrm{T} 375 \mathrm{C}$, in 56 transitional cell carcinoma of the urinary bladder in Turkey. The presence of FGFR 3 TD mutations and their correlation with clinico-pathological parameters were also analyzed in this study.

\section{MATERIAL AND METHODS}

\section{Materials}

Fifty-six urinary bladder transitional cell carcinoma cases from Denizli State Hospital, Department of Pathology archives, were included in this study. Among the 56 transitional cell carcinomas, 14 were classified as pTa, 23 as pT1, and 19 as pT2. In addition, 5 of them were graded as G1, 25 graded as G2, and 26 graded as G3. Median age at time of diagnosis was 65.5 years (range, 28-83 years) (Table 1). All transitional cell carcinomas were staged according to UICC criteria and graded according to WHO criteria. Six healthy men's genomic DNAs were used as the control group. This study was approved by the Pamukkale University School of Medicine Medical Ethics Committee.

\section{Genomic DNA}

DNA extraction from paraffin-embedded tissues was performed using the QIAamp DNA Mini-Kit (Qiagen, Hilden, Germany) according to the manufacturer protocol. 


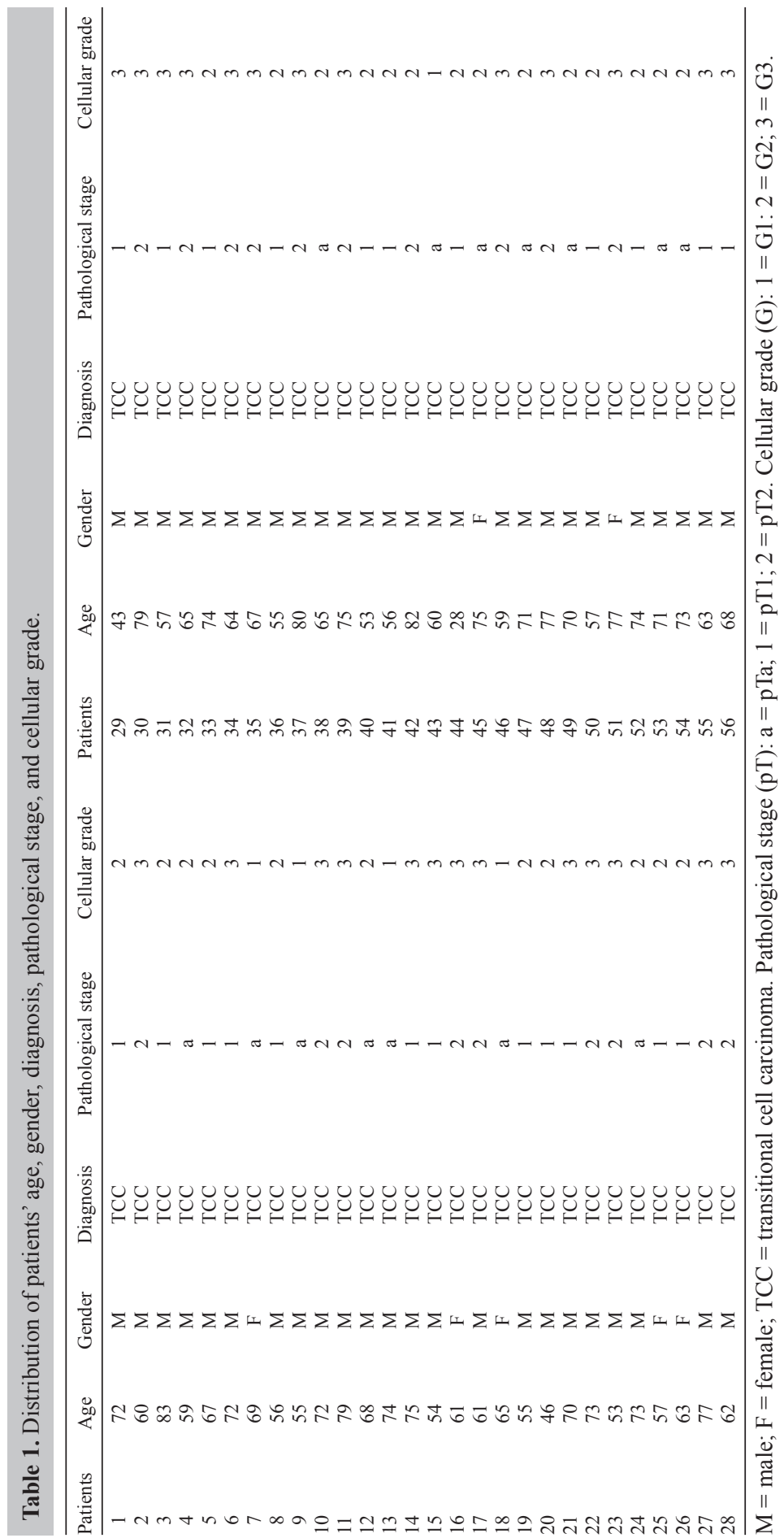




\section{DNA amplification and mutation analysis}

\section{Polymerase chain reaction (PCR) for each exon}

FGFR3 TD mutations were Arg248Cys (CGC $\rightarrow$ TGC) and Ser249Cys (TCC $\rightarrow$ TGC) in exon 7, and Gly372Cys (GGC $\rightarrow$ TGC) and Tyr375Cys (TAT $\rightarrow$ TGT) in exon 10. Mutation analyses of the related exons were performed by PCR-RFLP (restriction fragment length polymorphism) and DNA sequencing. The primers used in this study are listed in Table 2.

Table 2. Primers used for FGFR3 gene codon 248, 249, 372, 375 amplification.

\begin{tabular}{lclc}
\hline Codon & Exon & Primer sequence & PCR product (bp) \\
\hline 248,249 & 7 & F 5' CGGCAGTGGCGGTGGTGGTG 3' & 120 \\
& & R 5' AGCACCGCCGTCTGGTTG 3' & 270 \\
372,375 & 10 & F 5' CAGGCCAGGCCTCAACGCCC 3' & \\
\hline
\end{tabular}

$\mathrm{PCR}=$ polymerase chain reaction

All PCR amplifications were performed in a total volume of $50 \mu \mathrm{L}$ containing $10 \mu \mathrm{L}$ extracted DNA, $20 \mathrm{pM}$ of each forward and reverse primer, and $25 \mu \mathrm{L}$ HotStarTaq Master Mix [containing 2.5 U HotStarTaq DNA polymerase, 1X PCR buffer with $1.5 \mathrm{mM} \mathrm{MgCl}$, and 200 $\mu \mathrm{M}$ of each dNTP (Qiagen, Hilden, Germany)]. Thermal cycling conditions for PCR were as follows: initial activation of HotStarTaq DNA polymerase at $95^{\circ} \mathrm{C}$ for $15 \mathrm{~min}$, followed by 40 cycles of $95^{\circ} \mathrm{C}$ for $1 \mathrm{~min}, 67^{\circ} \mathrm{C}$ for $1 \mathrm{~min}$, and $72^{\circ} \mathrm{C}$ for $1 \mathrm{~min}$, with a final extension of $72^{\circ} \mathrm{C}$ for $10 \mathrm{~min}$ (exon 7); initial activation of HotStarTaq DNA polymerase at $95^{\circ} \mathrm{C}$ for $15 \mathrm{~min}$, followed by 40 cycles of $95^{\circ} \mathrm{C}$ for $1 \mathrm{~min}, 72^{\circ} \mathrm{C}$ for $1 \mathrm{~min}$, and $72^{\circ} \mathrm{C}$ for $1 \mathrm{~min}$, with a final extension of $72^{\circ} \mathrm{C}$ for $10 \mathrm{~min}$ (exon 10). PCR products were subjected to electrophoresis using an ethidium bromidestained $2 \%$ agarose gel and visualized under UV for the control of their specificity and accuracy.

\section{Screening for Arg248Cys and Ser249Cys mutations in exon 7 using RFLP analysis}

Screening for the FGFR3 $\operatorname{Arg} 248$ Cys mutation in exon 7 was performed by digestion with restriction endonuclease HaeII (New England Biolab, Beverly, MA, USA). Screening for the FGFR3 Ser249Cys mutation in exon 7 was performed by digestion with restriction endonuclease TseI (New England Biolab). The PCR product, $10 \mu \mathrm{L}$, was digested with $1 \mathrm{U}$ of each restriction enzyme in $20 \mu \mathrm{L}$ for $1 \mathrm{~h}$ at $37^{\circ} \mathrm{C}$ for A248C and at $65^{\circ} \mathrm{C}$ for S249C. Each product was screened on a 3\% Molecular Screening agarose gel (Roche Diagnostics GmbH, Mannheim, Germany), which was stained with ethidium bromide and photographed under ultraviolet light.

\section{Screening for Gly372Cys and Tyr375Cys mutations in exon 10 using sequence analysis}

FGFR3 exon 10 Gly372Cys and Tyr375Cys mutations were analyzed by direct DNA sequencing using the ABI PRISM 310 Genetic Analyzer at Iontek Laboratory, Istanbul, Turkey.

\section{Statistical analysis}

The relationship between the FGFR3 thanatophoric dysplasia mutations and patient 
gender or age was evaluated using the Student $t$-test; cellular grades were evaluated using the chi-square test for independence, and the SPSS 10.0 software was used for calculations. P $<$ 0.05 was taken as statistically significant.

\section{RESULTS}

The incidence of FGFR 3 thanatophoric dysplasia mutations located in exon 7, A248C and S249C, and in exon 10, G372C and T375C, was investigated in 56 transitional cell carcinomas of the urinary bladder. PCR-RFLP and direct DNA sequencing analysis revealed the presence of 4 different heterozygous mutations in 38 of the 56 urinary bladder transitional cell carcinoma cases.

The FGFR $3 \mathrm{~A} 248 \mathrm{C}$ mutation in exon 7 was detected in 7 of the 56 urinary bladder transitional cell carcinoma cases (12.5\%). If there were no mutations, a 120-bp PCR product was digested to 64- and 56-bp fragments by HaeII enzyme, naturally. When the A248C mutation in exon 7 was present, the 120-bp PCR product could not be digested by HaeII enzyme (Figure 1).

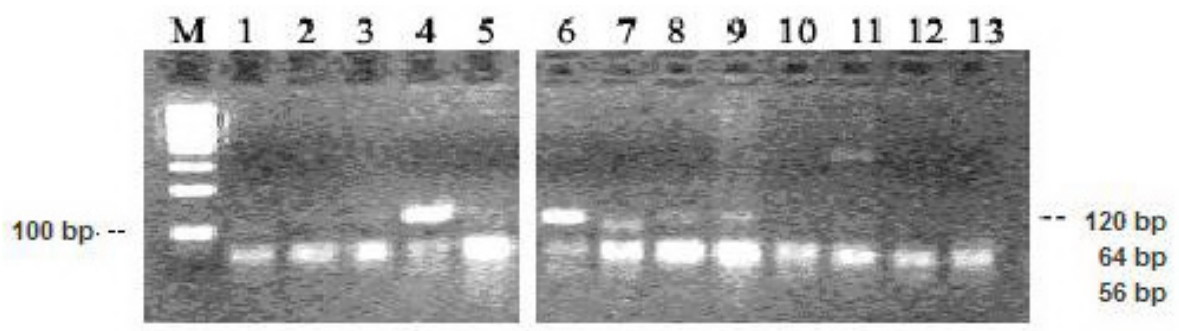

Figure 1. Representative photograph of the PCR products restricted with HaeII enzyme and analyzed on a $3 \%$ Molecular Screening agarose gel. Lanes 4, 6, 7, 8 and 9 are mutant for FGFR3 A248C. Lanes 1-3, 5, 10-13 are not mutant for FGFR3 A248C. M =100-bp marker.

The FGFR3 S249C mutation in exon 7 was detected in 28 of the 56 urinary bladder transitional cell carcinoma cases (50\%). When the S249C mutation was present, the PCR product of exon 7 was digested to 63-, 31- and 26-bp fragments by TseI enzyme. If there were no mutations, the 120-bp PCR product was digested to 94- and 26-bp fragments, naturally (Figure 2).

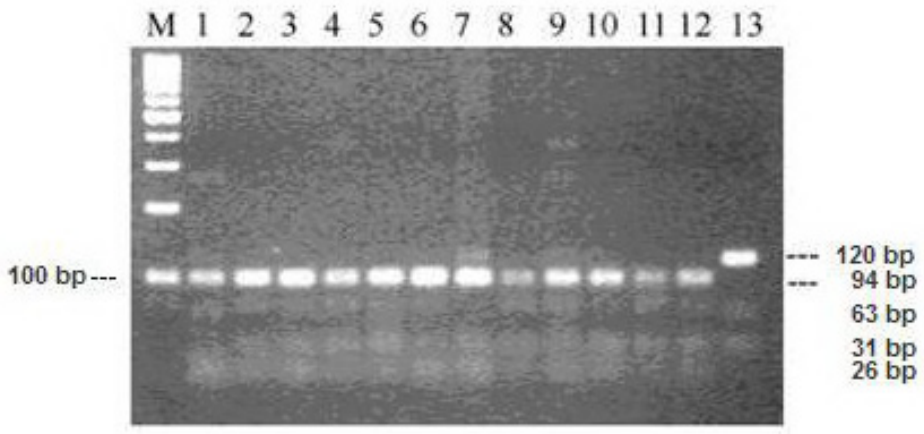

Figure 2. Representative photograph of the PCR products restricted with $T_{s} \mathrm{I}$ enzyme and analyzed on a $3 \%$ Molecular Screening agarose gel. Lanes 1-12 are mutant for FGFR3 S249C. Lane 13 is not mutant for FGFR3 S249C. $M=100$-bp marker. 
The FGFR 3 G372C mutation in exon 10 was not detected in any of the 56 urinary bladder transitional cell carcinoma cases.

The FGFR 3 T375C mutation in exon 10 was detected in 3 of the 56 urinary bladder transitional cell carcinoma cases (5.4\%) by direct DNA sequencing (Figure 3 ).

A

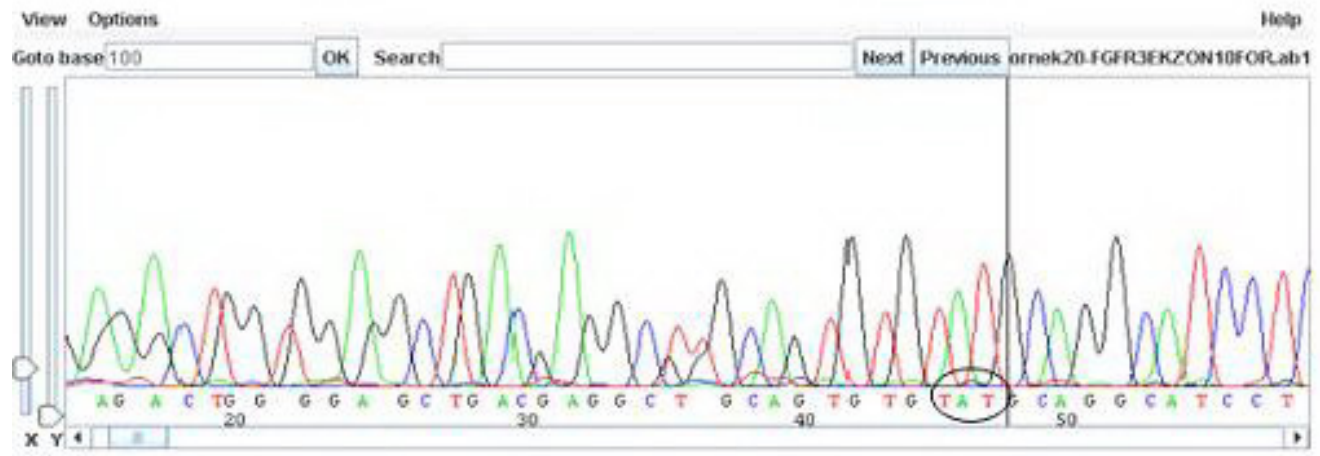

B

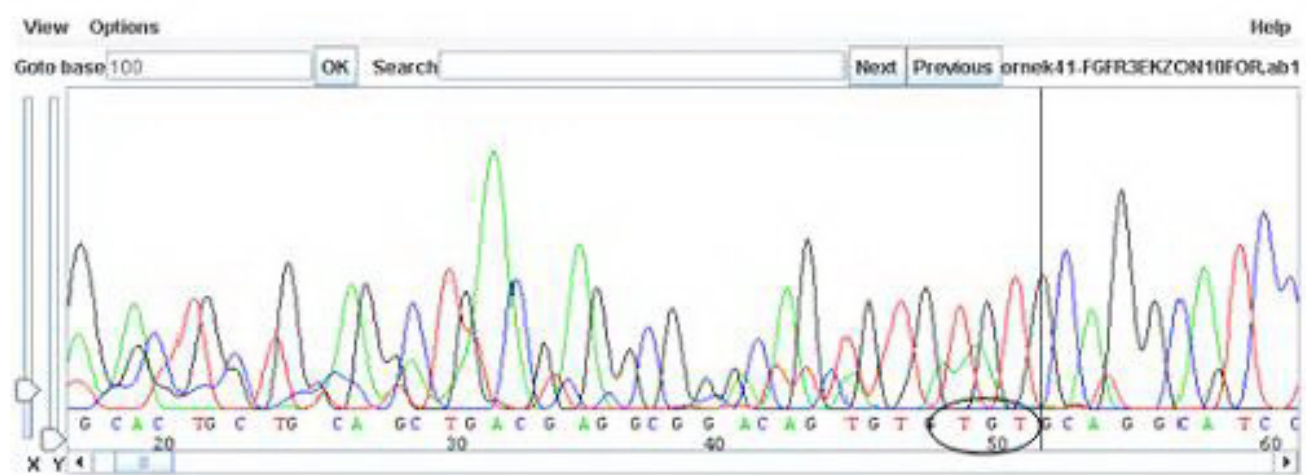

Figure 3. Representative electropherogram for FGFR3 exon 10 T375C mutation using the sequence analysis. A. Bladder tumor case No. 20 showing normal codon for FGFR3 T375C. B. Bladder tumor case No. 16 showing $\mathrm{TAT} \rightarrow \mathrm{TGT}$ alteration for FGFR3 exon $10 \mathrm{~T} 375 \mathrm{C}$ mutation.

Four of the patients had both FGFR3 A248C and S249C mutations in exon 7, whereas one patient had both FGFR3 S249C and T375C mutations in exon 7 and exon 10, respectively.

In the male control group, FGFR3 thanatophoric dysplasia mutations A248C, S249C, G372C, and T375C were not detected. The distribution of overall FGFR3 mutations (codons 248, 249, 372, and 375) in relation to clinico-pathological features is shown in Table 3. 


\begin{tabular}{|c|c|c|c|c|c|c|}
\hline Characteristic & $\mathrm{N}(\%)$ & A248C & S249C & G372C & $\mathrm{T} 375 \mathrm{C}$ & Results of thanatophoric dysplasia mutations \\
\hline \multicolumn{7}{|l|}{ Gender } \\
\hline Female & $7(12.5 \%)$ & $1(14.3 \%)$ & $6(85.7 \%)$ & - & $1(14.3 \%)$ & $6(85.7 \%)$ \\
\hline Male & $49(87.5 \%)$ & $6(12.2 \%)$ & $22(44.9 \%)$ & - & $2(4.1 \%)$ & $27(55.1 \%)$ \\
\hline \multicolumn{7}{|c|}{ Tumor classification (pT) } \\
\hline a & $14(25 \%)$ & $2(14.3 \%)$ & $6(42.9 \%)$ & - & $1(7.1 \%)$ & $8(57.1 \%)$ \\
\hline 1 & $23(41.1 \%)$ & $2(8.7 \%)$ & $12(52.2 \%)$ & - & $1(4.3 \%)$ & $14(60.9 \%)$ \\
\hline 2 & $19(33.9 \%)$ & $3(15.8 \%)$ & $10(52.6 \%)$ & - & $1(5.3 \%)$ & $11(57.9 \%)$ \\
\hline \multicolumn{7}{|c|}{ Cellular grade $(\mathrm{G})$} \\
\hline 1 & $5(8.9 \%)$ & $1(20 \%)$ & $1(20 \%)$ & - & - & $2(40 \%)$ \\
\hline 2 & $25(44.6 \%)$ & $3(12 \%)$ & $14(56 \%)$ & - & $2(8 \%)$ & $17(68 \%)$ \\
\hline 3 & $26(46.4 \%)$ & $3(11.5 \%)$ & $13(50 \%)$ & - & $1(3.8 \%)$ & $14(53.8 \%)$ \\
\hline
\end{tabular}

\section{DISCUSSION}

In this study, we analyzed the incidence of FGFR3 TD mutations in 56 bladder cancer patients at various stages and grades. Four different FGFR3 TD mutations were selected (A248C, S249C, G372C, T375C), in which they were analyzed in previous studies from different countries, except Turkey. The S249C mutation (TCC $\rightarrow$ TGC) was the most frequently observed FGFR 3 mutation in bladder tumors in our study (28 of 56 patients showed the S249C mutation, 50\%). The other mutations were less frequently observed in our study: 7 of 56 patients with the $\mathrm{A} 248 \mathrm{C}$ mutation, no patient with the $\mathrm{G} 372 \mathrm{C}$ mutation, and 3 of 56 patients with the T375C mutation. Evaluation of the relationship between presence of FGFR3 TD mutations and patient gender/age revealed that there was no significant correlation between the occurrence of FGFR 3 mutations and patient's age or gender (Table 3 ). There was also no significant correlation between the presence of FGFR3 mutations and tumor grade or stage in our study.

FGFR 3 mutations have been implicated in tumorigenesis for sometime (Basilico and Moscatelli, 1992). Somatic FGFR3 mutations identical to those found in thanatophoric dysplasia and SADDAN have been associated with rare cases of human multiple myeloma. Some of the studies have reported that low-stage and low-grade bladder tumors are associated with FGFR3 mutations (Cappellen et al., 1999) and alterations on chromosome 9 (Van Tilborg et al., 2002; Hirao et al., 2005). Billerey et al. (2001) investigated the relationship between FGFR3 mutations and tumor stage and found that the frequency of FGFR3 mutations was high in pTa tumors (74\%). FGFR 3 mutations were present in only $21 \%$ of pT 1 and $16 \%$ of pT2-4 tumors. The S249C mutation (TCC $\rightarrow$ TGC) is the most frequent FGFR3 mutation in bladder tumors ( 33 of $48,69 \%$ ). Other researchers have also reported similar findings, such as Kimura et al. (2001) who detected TD mutations of the FGFR3 in 25 of 81 cases of transitional cell carcinoma of the bladder (30.9\%). This is in agreement with Wang et al. (1999)'s findings in which FGFR3 mutations were detected in 9 of 26 bladder carcinomas (35\%). Van Rhijn et al. (2001) detected 34 point mutations in 72 bladder carcinomas (30 at codon 249, 1 at codon 248, and 2 at codon 372). In their findings, all tumors with FGFR3 mutation were pTa and grade 1 or 2 (Van Rhijn et al., 2001). Otto et al. (2009) found that all urothelial samples in their groups showed a wild-type sequence for FGFR3. They suggested for these data that mutations in the $F G F R 3$ are not the earliest genetic alterations in bladder carcinogenesis, and they thought that these findings are associated with a hyper-proliferative phenotype in the 
urothelium. They also suggested that chromosomal alterations such as deletions on chromosome 9q could play a more important role in early urothelial alteration than mutational FGFR3 activation (Otto et al., 2009). Tomlinson et al. (2007) published data showing that FGFR 3 mutations are found mostly in urothelial carcinoma patients with low-stage and lowgrade tumors. They detected a frequency of mutations in low-stage urothelial carcinoma that was intermediate (58\%) compared to those reported in studies performed in The Netherlands (67\%) (Tomlinson et al., 2007). Van Rhijn et al. (2002) found in one of their study that 79 pTaG1 tumors consisted of 62 papillary urothelial neoplasms of low malignant potential and 17 low-grade papillary urothelial carcinomas, and that according to the 2004 WHO classification system, $86 \%$ had the FGFR3 mutation. These results confirmed the association of mutation with low-risk urothelial carcinoma and indicated that there is a strong molecular relationship between urothelial papilloma and low-grade urothelial carcinoma (Van Rhijn et al., 2002). Miyake et al. (2007) showed FGFR3 mutations in 12 of $13(92.3 \%)$ tumor tissues and 11 of $13(84.6 \%)$ urine samples from patients with superficial bladder cancer, while no mutations were detected in tissues and/or urine samples from patients with muscle-invasive bladder cancer or chronic cystitis. Kompier et al. (2009) showed that in patients with an FGFR3 mutant primary tumor, mutations were detected in $81 \%$ of recurrence events. The $19 \%$ wild-type recurrences in this group, which would escape detection by potential surveillance with this assay, were 18 non-muscle-invasive G1/2 tumors, two pTaG1/2 with adjacent CIS, and one pT2G2 tumor.

When the results of the $F G F R 3$ thanatophoric dysplasia mutations in exon 7, A248C and S249C, and in exon 10, G372C and T375C, were analyzed one by one or as a group, our data suggested that these mutations are detected homogenously regardless of the tumor classification and tumor grade in our study, in contrast to the findings of previous research reports. Further study is ongoing to elucidate the significance of FGFR 3 mutations detectable in urine samples in the clinical management of bladder cancer patients. It would also be appropriate to include more early-stage and low-grade tumor samples in this research project.

\section{ACKNOWLEDGMENTS}

Research supported by Pamukkale University Research Grant (\#2006SBE002).

\section{REFERENCES}

Basilico C and Moscatelli D (1992). The FGF family of growth factors and oncogenes. Adv. Cancer Res. 59: 115-165.

Billerey C, Chopin D, Aubriot-Lorton MH, Ricol D, et al. (2001). Frequent FGFR3 mutations in papillary non-invasive bladder (pTa) tumors. Am. J. Pathol. 158: 1955-1959.

Cappellen D, De Oliveira C, Ricol D, de Medina S, et al. (1999). Frequent activating mutations of FGFR3 in human bladder and cervix carcinomas. Nat. Genet. 23: 18-20.

Chesi M, Brents LA, Ely SA, Bais C, et al. (2001). Activated fibroblast growth factor receptor 3 is an oncogene that contributes to tumor progression in multiple myeloma. Blood 97: 729-736.

Chow NH, Cairns P, Eisenberger CF, Schoenberg MP, et al. (2000). Papillary urothelial hyperplasia is a clonal precursor to papillary transitional cell bladder cancer. Int. J. Cancer 89: 514-518.

Hirao S, Hirao T, Marsit CJ, Hirao Y, et al. (2005). Loss of heterozygosity on chromosome 9q and p53 alterations in human bladder cancer. Cancer 104: 1918-1923.

Jaye M, Schlessinger J and Dionne CA (1992). Fibroblast growth factor receptor tyrosine kinases: molecular analysis and signal transduction. Biochim. Biophys. Acta 1135: 185-199. 
Johnson DE and Williams LT (1993). Structural and functional diversity in the FGF receptor multigene family. Adv. Cancer Res. 60: 1-41.

Kimura T, Suzuki H, Ohashi T, Asano K, et al. (2001). The incidence of thanatophoric dysplasia mutations in FGFR3 gene is higher in low-grade or superficial bladder carcinomas. Cancer 92: 2555-2561.

Kompier LC, Van Der Aa MN, Lurkin I, Vermeij M, et al. (2009). The development of multiple bladder tumour recurrences in relation to the FGFR3 mutation status of the primary tumour. J. Pathol. 218: 104-112.

Lopez-Beltran A, Alvarez-Kindelan J, Luque RJ, Blanca A, et al. (2008). Loss of heterozygosity at 9q32-33 (DBC1 locus) in primary non-invasive papillary urothelial neoplasm of low malignant potential and low-grade urothelial carcinoma of the bladder and their associated normal urothelium. J. Pathol. 215: 263-272.

Miyake M, Sugano K, Kawashima K, Ichikawa H, et al. (2007). Sensitive detection of FGFR3 mutations in bladder cancer and urine sediments by peptide nucleic acid-mediated real-time PCR clamping. Biochem. Biophys. Res. Commun. 362: 865-871.

Obermann EC, Junker K, Stoehr R, Dietmaier W, et al. (2003). Frequent genetic alterations in flat urothelial hyperplasias and concomitant papillary bladder cancer as detected by CGH, LOH, and FISH analyses. J. Pathol. 199: 50-57.

Otto W, Denzinger S, Bertz S, Gaumann A, et al. (2009). No mutations of FGFR3 in normal urothelium in the vicinity of urothelial carcinoma of the bladder harbouring activating FGFR3 mutations in patients with bladder cancer. Int. $J$. Cancer 125: 2205-2208.

Partanen J, Vainikka S and Alitalo K (1993). Structural and functional specificity of FGF receptors. Philos. Trans. R. Soc. Lond. B. Biol. Sci. 340: 297-303.

Perez-Castro AV, Wilson J and Altherr MR (1997). Genomic organization of the human fibroblast growth factor receptor 3 (FGFR3) gene and comparative sequence analysis with the mouse Fgfr3 gene. Genomics 41: 10-16.

Sugano K and Kakizoe T (2006). Genetic alterations in bladder cancer and their clinical applications in molecular tumor staging. Nat. Clin. Pract. Urol. 3: 642-652.

Tomlinson DC, Baldo O, Harnden P and Knowles MA (2007). FGFR3 protein expression and its relationship to mutation status and prognostic variables in bladder cancer. J. Pathol. 213: 91-98.

Van Oers JM, Adam C, Denzinger S, Stoehr R, et al. (2006). Chromosome 9 deletions are more frequent than FGFR3 mutations in flat urothelial hyperplasias of the bladder. Int. J. Cancer 119: 1212-1215.

Van Rhijn BW, Lurkin I, Radvanyi F, Kirkels WJ, et al. (2001). The fibroblast growth factor receptor 3 (FGFR3) mutation is a strong indicator of superficial bladder cancer with low recurrence rate. Cancer Res. 61: 1265-1268.

Van Rhijn BW, Montironi R, Zwarthoff EC, Jobsis AC, et al. (2002). Frequent FGFR3 mutations in urothelial papilloma. J. Pathol. 198: 245-251.

Van Tilborg AA, de Vries A, de Bont M, Groenfeld LE, et al. (2002). The random development of LOH on chromosome 9q in superficial bladder cancers. J. Pathol. 198: 352-358.

Wang Y, Spatz MK, Kannan K, Hayk H, et al. (1999). A mouse model for achondroplasia produced by targeting fibroblast growth factor receptor 3. Proc. Natl. Acad. Sci. U. S. A. 96: 4455-4460. 